\title{
UMA ANÁLISE DA SALA DE AULA PARA A FORMAÇÃO DO PROFESSOR ${ }^{1}$
}

\author{
Maria da Conceição Passeggi \\ Programa de Pós-graduação em Educação \\ Universidade Federal do Rio Grande do Norte
}

Luis Passeggi

Programa de Pós-graduação em Estudos da Linguagem Universidade Federal do Rio Grande do Norte

\section{INTRODUÇÃO}

Para muitos pesquisadores das ciências da linguagem $e$ das ciências da educação é difícil conceber a sala de aula como um objeto de pesquisa pleno. Os processos discursivos subjacentes à interação didática, os rituais da instituição escolar, as atitudes e comportamentos negociados na sala de aula, escapam, geralmente, à sua consciência: a aula simplesmente acontece. Uma vez iniciada a pesquisa, os dados empíricos parecem-lhes ainda mais desconcertantes. A sala de aula vai, aos poucos, descortinando-se como um universo complexo e dificil de ser apreendido: ao mesmo tempo próximo e arredio. Como evidenciar que, nesse espaço institucionalizado, professor e aluno (re)constróem, permanentemente, saberes, valores e crenças? Como tornar visiveis os procedimentos subjacentes aos conflitos e negociações que

Este trabalho é um produto do projeto "Explicar e fazer(-se) compreender. Atividades de reformulaçào em sala de aula", de M. C. Passeggi, Base de Pesquisa Ensino e Linguagem. Pós-graduação em Educação - Depto. de Educação da UFRN, e do projeto "Lingüistica Aplicada e Modelos Lingüísticos", de L. Passeggi, Base de Pesquisa Linguagem. Interação e Formaçĩo, Pós-graduação em Estudos da Linguagem - Depto. de Letras da UFRN. Financiamento: PIBIC-CNPq e Pró-reitoria de Pesquisa e Pós-graduação da UFRN. Contato com os autores: passeggi@cabugisat.com.br 
se enlaçam e desenlaçam nesse mundo, ao mesmo tempo familiar e desconhecido?

O presente trabalho propõe o estudo de uma situação de sala de aula extremamente freqüente em nossas escolas: trata-se da aula baseada no texto didático, na qual o professor apresenta e explica esse texto aos seus alunos, interagindo a partir dele. Assim, focalizaremos enunciados que se referem, na sala de aula, aos conteúdos de ensino, e que incluem tanto aqueles contidos no livro didático quanto os decorrentes da interação professor /aluno. A opção por esse recorte justificase porque, apesar de o uso dos textos ser a prática costumeira - e secular - das situações de ensino/aprendizagem formal, ele tem sido, paradoxalmente, relativamente pouco investigado pelas pesquisas sobre a sala de aula ${ }^{2}$. Complementarmente, nosso trabalho tem uma preocupação prática, no sentido contribuir para a melhoria do desempenho do professor em sala de aula. Procuraremos apresentar instrumentos de análise que permitam sua auto-observação e a (re)invenção de sua prática pedagógica: para o professor, esse será o melhor caminho para uma prática auto-reflexiva e duradoura.

De um ponto de vista teórico e metodológico, situamonos no âmbito de uma lingüística aplicada baseada numa abordagem lingüístico-discursiva da comunicação em sala de aula, perspectiva que vimos desenvolvendo em diversos trabalhos (Passeggi, M. C., 1998a, 1998b; Passeggi, L., 1998a, 1998b). Ela permite uma interface consistente, e mutuamente enriquecedora, com correntes teóricas particularmente adequadas aos nossos propósitos: lingüística da enunciação (Fuchs, 1994; Authier-Revuz, 1984, 1998; Moirand, Peytard, 1992), lingüistica interacionista (Kerbrat-Orecchioni, 1990, 1992, 1994; Vion, 1992; Bakhtin, 1992), etnometodologia lingüistica (Gülich e Kotschi, 1987; Gülich, 1992), e, sobretudo, o interacionismo socio-discursivo (Bronckart, 1997). Os dados empíricos que utilizamos reúnem transcrições de aulas das diversas disciplinas do ensino fundamental e médio, coletadas em escolas da rede pública de Natal e do interior do estado do

Destacamos os trabalhos de Kleiman 1993; Bortoni \& Lopes, 1991; Coracini, 1995; Chiappini et al, 1997. 
Rio Grande do Norte, assim como transcrições de aulas e situações experimentais no ensino superior, na UFRN.

Em nossa exposição, apresentaremos, em primeiro lugar, alguns aspectos teóricos e metodológicos de nossa abordagem da sala de aula; em segundo lugar, examinaremos seu rendimento prático para a formação do professor.

\section{ASPECTOS TEÓRICOS E METODOLÓGICOS}

\section{As seqüências discursivas didáticas e 0 triângulo pedagógico}

Toda situação de interação didática articula-se em torno de três pólos, pelo menos: o professor, o aluno, e os saberes (escolares e espontâneos). O saber escolar, sistematizado socio-historicamente, tem como principal vetor os textos, orais e escritos, em torno dos quais se organiza a interação didática professor/aluno, os quais determinam largamente a formação do aluno, ao longo de sua escolaridade, como (bom ou mau) leitor, como (bom ou mau) produtor de textos, com amplas repercussões sobre o processo de aquisição dos conhecimentos, e sobre sua atuação social.

A circulação do saber sistematizado, na sala de aula, concretiza-se em seqüencias discursivas de enunciados que visam à transmissão e aquisição dos conteúdos de ensino. Essas seqüencias colocam: (a) uma visada de transmissão/aquisição dos conhecimentos, ou seja, uma visada de "didaticidade", no sentido de trazer a outros locutores novos saberes (Beacco, Moirand, 1995, p. 33); (b) objetos de discurso fornecidos basicamente pelo tecnoleto próprio de uma dada área de conhecimento. Designaremos essas seqüências como "seqüências de conteúdo", ou "seqüências didáticas", forma abreviada para indicar as seqüências discursivas que visam à transmissão/aquisição dos conteúdos de ensino (ver Passeggi, L. A., 1998b, para uma análise). A título de exemplo, consideremos as seguintes seqüências ( $P$ : professor; $A$ : aluno): 
Ex. 1 - Português, $5^{\text {a }}$ série.

P. então nós vimos ontem que o verbo é uma palavra que indica o que ? ação... não é? uma palavra pra ser verbo é preciso que ela indique ação...não é? ação...por exemplo... (??)

A - professora...a palavra problema é o quê?

$P$ - problema indica ação? não dá

A - ação

P - como é que eu vou dizer eu problema...tu problema...como é que eu vou dizer isso? indica ação...movimento a palavra problema?

A - não

Ex. 2 - Ciências, $6^{\text {a }}$ série.

$P$ - em seguida vem o cobre...o cobre, ele é muito importante na eletrotécnica...é muito empregado...eh...nas linhas de transmissão de eletricidade, mas esses fios de postes são de quê?

A - cobre

P - de cobre...por que? porque ele é um metal (.) eh...eh...muito que...que conduz...eh eh...muito bom na condução de eletricidade...quer dizer leva...conduz a eletricidade...é um bom condutor de eletricidade

Ex. 3 - Educação Artistica, $7^{a}$ série.

A - Bom... o Realismo foi uma corrente, aliás, uma tendência da História da Arte que está contida no Neoclassicismo. O realismo surgiu como tendência na pintura no final do século XVIII, hum... ela possui todas as caracteristicas do Neoclassicismo, que vocês já viram né.

Ex. 4 - Matemática, $6^{\mathrm{a}}$ série.

P - Multiplica 5 vezes 1. Prestem atenção no que eu vou dizer. Quando tiver um número na frente de um parêntese esse número está multiplicando todos os números que estäo dentro do parênteses... cinco vezes $2 \ldots 10 \times \ldots$ menos 5 vezes...

A - (ininteligivel)

P - Pronto. Como é o nome dessa expressão que a gente tem ai? (S)

P - Qual é o nome dessa expressão $10 x-5=2 x+8$ ? Que expressão é essa?

A - Equaçäo.

P - Por que que é equação? 
As seqüências didáticas são elaboradas conjuntamente pelo professor e pelo aluno com o objetivo de construir um saber sistematizado, largamente predeterminado pela instituiçăo escolar. Articulam-se com outros tipos de seqüência, também presentes na interação didática em sala de aula, mas que não trataremos aqui: seqüências das rotinas, seqüências das representações sociais, seqüências pessoais e seqüências externas (Passeggi, L., op. cit.). As seqüências didáticas são o espaço verbal da figuração, diferenciação e da legitimação dos saberes: professor vs alunos, saber sistematizado vs saber espontâneo. Sua organização interna precisa ser ainda descrita, embora possamos perceber atos de discurso característicos, tais como: definir, exemplificar e explicar conteúdos. Essas seqüências são centrais para a função instrucional da escola, sendo percebidas, freqüentemente, como sua razão de ser.

A ancoragem da interação no texto didático escrito coloca um problema da ordem do "saber" e do "dizer". O professor, enquanto agente mediador do processo educativo, interage na tentativa de "adaptar" e "explicar" ao aluno os conteúdos do texto. Nessa tarefa, ele deve, por um lado, dominar, de algum modo, o conteúdo e o gênero do texto, i.e. o "saber" e "o dizer"; por outro lado, deve considerar a percepção do aluno sobre o texto. O aluno, enquanto agente do seu processo de formação, interage na tentativa de integrar ao seu conhecimento de mundo as novas informações.

Representaremos a interação professor / texto / aluno recorrendo à imagem do triângulo pedagógico, proposto por Hussaye (1988), e adaptando-o aos nossos propósitos.

Figura 1 - O triângulo pedagógico

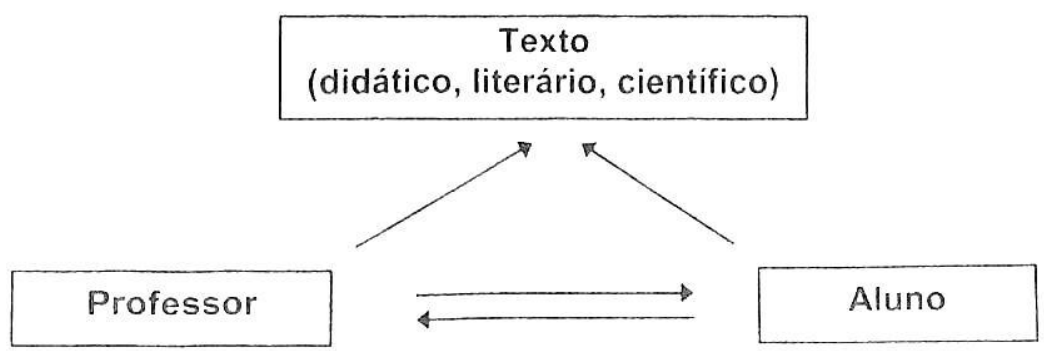


O esquema evidencia uma dupla perspectiva interacional: (a) a interação leitor/texto; (b) a interação professor/texto/aluno. As flechas na direção do texto representam a interação leitor/texto e simbolizam as operações de compreensão e de interpretação do texto escrito, realizadas tanto pelo professor quanto pelo aluno. As flechas que se cruzam na parte inferior do triângulo representam a interação professor/texto/aluno e simbolizam as estratégias de negociação das significações (Kramsch, 1991), realizadas com base no contrato comunicativo da sala de aula.

\section{Texto fonte, texto mediador e texto alvo}

O triângulo pedagógico define uma situação que tem como ponto de partida um texto didático escrito, cujo conteúdo deve ser apresentado e explicado pelo professor e compreendido e adquirido pelo aluno. Baseando-nos nessa situação, concebemos um modelo que supõe um processo envolvendo três tipos de textos que se articulam na sala de aula: o texto fonte, texto escrito, retirado do livro didático; o texto mediador, texto oral, produzido pelo professor e o aluno em sala de aula; o texto alvo, normalmente escrito, produzido pelo aluno, no momento de uma prova ou avaliação, ou logo após a explicação do texto inicial (ver Passeggi, M. C., 1998a).

$\mathrm{Na}$ articulação desses textos: texto fonte $\rightarrow$ texto mediador $\rightarrow$ texto alvo, alternam-se diferentes enunciadores (o autor, o professor e o aluno), que produzem duas modalidades de texto, oral e escrita, implicando três tipos de interação, conforme mostra a figura abaixo:

Figura 2 - A articulação dos textos na sala de aula

\begin{tabular}{clll}
\hline TEXTOS & ENUNCIADORES & $\begin{array}{l}\text { MODALIDADES } \\
\text { DE PRODUÇÃO }\end{array}$ & INTERAÇÃO \\
\hline Texto fonte & Autor & Produção escrita & $\begin{array}{l}\text { Autor/textol } \\
\text { leitor }\end{array}$ \\
Texto mediador & Professorlaluno & Produção oral & $\begin{array}{l}\text { Professor/textol } \\
\text { aluno }\end{array}$ \\
Texto alvo & Aluno & Produção escritata & $\begin{array}{l}\text { Aluno/textol } \\
\text { professor }\end{array}$ \\
\hline
\end{tabular}


A tendência, de certa forma natural, tem sido a de valorizarmos, por um lado, as duas pontas desse percurso: o texto do livro didático (texto-fonte) ${ }^{3}$ e o texto produzido pelo aluno (texto-alvo), e a de reduzirmos, por outro lado, a importância do texto-mediador na construção dos conhecimentos. Ora, mesmo se, reconhecidamente, uma das funções da escola é ensinar a ler e a escrever (nas suas acepções mais amplas), é fundamental perceber que a maior parte do processo de ensino/aprendizagem, na sala de aula, passa pela interação verbal entre o professor e o aluno.

Nessa perspectiva, o papel do professor não é o de um "mero intermediário", cuja função é a de colocar em contato os dois "principais interessados": o aluno e o texto. O tempo e a qualidade da fala do professor configura-o no papel de "mediador privilegiado", i.e., aquele por quem passa obrigatoriamente o "saber" (Hussaye, 1988) e, acrescentamos, o "saber dizer". Na medida em que ignoramos a importância do texto-mediador, perdemos de vista a compreensão do processo de construção conjunta dos conhecimentos na interação. Para Marcuschi (1988, p. 40), é sugestiva a hipótese de que o rendimento escolar dependeria da natureza do texto produzido oralmente pelo professor, seja quanto às estruturas lingüisticas, ao léxico ou à forma discursiva da informação.

Para ressaltarmos a importância do texto-mediador na construção dos conhecimentos, a perspectiva adotada por Bronckart (1997) parece-nos pertinente para os nossos propósitos. Ele sugere que, ao invés de centrar-nos unicamente nos recursos mentais ou "cognitivos" dos sujeitos (i.e. dos alunos), enquanto "entidades autônomas", devemos levar em consideração o papel das "intervenções formativas", realizadas na interação social. Na escola, é através dessas intervenções, deliberadas ou não, que se constróem as capacidades discursivas do aluno. Portanto, o "saber" e o "saber dizer" adquirem-se e desenvolvem-se no contato com o outro sob o efeito da "mediação". Podemos, mais raramente,

A busca do texto "interessante" ou do método "ideal" poderia estar relacionada com a representação que têm os professores do livro didático como o "objeto mágico" da prática docente. 
conceber os efeitos inversos de uma "contra-mediação" (Delamotte-Legrand, 1997) nas relações entre aprendizagem e desenvolvimento.

Daí o interesse de refletirmos sobre o texto-mediador, procurando focalizar os procedimentos lingüísticos e interacionais do professor em sala de aula, valorizando sua participação do professor no processo de construção dos conhecimentos.

\section{A Competência comunicativa e a construção do texto- mediador}

A análise do texto-mediador indica que, na produção desse texto, o professor encontra diferentes tipos de problemas, relacionados com os seus conhecimentos (lingüístico, discursivo-textual, enciclopédico, interacional) e que remetem, grosso modo, à sua competência comunicativa. O esforço para resolvê-los deixa marcas no texto. E é justamente a partir dessas marcas que podemos inferir as estratégias utilizadas na sua tarefa de mediar os conteúdos do texto-fonte.

A noção de competência comunicativa, proposta por Hymes, no início dos anos 70, chama a atenção do professor para uma concepção interacional da linguagem, essencialmente calcada nas relações interpessoais, vivenciadas em situações de comunicação cotidianas. Na perspectiva de uma lingüistica interacionista, Kerbrat-Orecchioni (1990) considera a competência comunicativa como um dispositivo complexo de aptidões, no qual os saberes lingüísticos e saberes sociais encontram-se irredutivelmente entrelaçados. A competência comunicativa manifesta-se tanto na compreensão quanto na produção de textos orais e escritos. Ao integrar as noções de "conhecimento" e de "habilidade", ela coloca em evidência as dimensões cognitiva e social da linguagem. Retomamos a noção de competência comunicativa como categoria de observação e de intervenção na formação inicial e continuada, dos professores. 
Admitiremos que o desempenho do professor relacionase com quatro tipos de conhecimentos e de habilidades (ver Coltier, 1986; Moirand, 1990; Moirand, Peytard, 1992; KerbratOrecchioni, 1990; Kramsch, 1991):

1) A competência lingüística e paralingüística compreende o conhecimento da lingua e das suas regras de funcionamento, assim como a habilidade para compreender $\mathrm{e}$ produzir frases, com base nessas regras (fonéticas, prosódicas, gramaticais).

A condição básica para a realização da interação verbal é o conhecimento da língua e de suas regras de funcionamento, no sentido estrito, da competência lingüística, com seu componente gramatical e lexical.

É um truísmo, mas não é inútil lembrar, haja vista às tentações atuais de eliminar o sentido lingüistico em benefício de abordagens totalmente psicolingüisticas ou sociolingüísticas: para compreender um texto, é preciso evidentemente, em primeiro lugar, compreender o sentido das palavras que o compõem. (Kleiber, G. 1987. apud Kerbrat-Orecchioni, 1990; traduzimos).

Entre falantes de uma mesma língua, essa condição é, em grande parte, preenchida tanto professor quanto pelo aluno, uma vez que a interação realiza-se na sua língua materna.

2) A competência enciclopédica diz respeito ao conjunto de saberes espontâneo e/ou sistematizado sobre fenômenos, fatos, idéias etc., e a habilidade para formular, compreender e internalizar novas informações.

3) A competência discursivo-textual concerne 0 conhecimento e a habilidade para identificar e produzir diferentes tipos de textos (orais e escritos) em função de diversos parâmetros que estruturam as frases em seqüências textuais (descritivas, narrativas, argumentativas (Adam, 1992) de acordo com modelos discursivos específicos (didático, literário, jornalístico etc.).

4) A competência interacional compreende 0 conhecimento de normas sociais determinadas pela instituição 
escolar e a habilidade para regular a interação, de acordo com os momentos específicos da situação de ensino/aprendizagem formal. Incluem-se, aqui, a capacidade de descentração e de negociação.

$\mathrm{Na}$ interação, esses conhecimentos e habilidades encontram-se irredutivelmente entrelaçados. Por outro lado, eles são adquiridos na interação social e são "adaptáveis" e "modificáveis" face ao contexto interlocutivo, mas também podem, eventualmente, "degradar-se" por motivos de ordem psicológica ou física - distúrbios da linguagem (KerbratOrecchioni,1990). Esses fatores são importantes para os propósitos de intervenção na formação inicial e continuada do professor. Nossa indagação vai no sentido de tentar compreender como a competência comunicativa se projeta no discurso da sala de aula e quais as suas conseqüências para o processo de intercompreensão.

As dificuldades ou potencialidades do professor para explicar de forma clara e coerente os textos do livro didático decorreriam:
a) do
conhecimento enciclopédica)?
do
assunto
(competência
b) do uso de meios lingüísticos (competência lingüística)?
c) do (des)conhecimento da composição textual característica do discurso da sala de aula e/ou daquelas do texto-fonte (competência discursivo-textual)?
d) do (des)alinhamento do seu discurso às normas conversacionais necessárias ao sucesso da interação didática (competência conversacional)?

Haveria uma incidência sistemática sobre alguns deles? Sobre todos ao mesmo tempo? Algumas disciplinas exigiriam prioritariamente um certo tipo de competência?

Como afirma Kramsch (1991), ninguém detém completamente essas competências. Daí o recurso às estratégias interativas, compreendidas como o esforço mútuo dos co-enunciadores para negociarem a construção da significação. Examinemos, a seguir, aquelas decorrentes da atividades de reformulação: repetição, correção, paráfrase. 


\section{As atividades de reformulação}

Como todo texto se constrói no diálogo com outros textos (Bakhtin,1992), a construção do texto-mediador têm como objetivo a (re)construção dos saberes veiculados e/ou sugeridos pelo o texto-fonte. O procedimento lingüístico crucial nesse processo são as atividades de reformulação, intertextuais e intratextuais ${ }^{4}$. Neste trabalho, interessa-nos a reformulação inter-textual, que consiste, a partir de um texto texto-fonte, em realizar um novo texto, o texto reformulador: texto mediador ou texto alvo.

Distinguimos três atividades básicas de reformulação: a repetição, a correção e a reformulação parafrástica ${ }^{5}$.

Diremos que ocorre uma repetição intertextual quando, por exemplo, o professor retoma, integralmente, no texto-reformulador, enunciados do texto de origem.

Figura 3

\begin{tabular}{l|l}
\hline TEXTO-FONTE & TEXTO-MEDIADOR \\
\hline $\begin{array}{l}\text { O Rio Grande do Norte embora } \\
\text { seja um dos menores estados }\end{array}$ & $\begin{array}{l}\text { P - ai, aqui, olhe, o Rio } \\
\text { brasileiros possui diferenças de do Norte embora seja um }\end{array}$ \\
$\begin{array}{l}\text { relevo, clima, solo e atividades } \\
\text { econômicas }\end{array}$ & $\begin{array}{l}\text { dos menores estados brasileiros } \\
\text { possui diferenças de relevo/ } \\
\text { relevo é o que? Partes altas e } \\
\text { baixas, clima que é o que? A } \\
\text { temperatura certo? se é seco, se } \\
\text { é quente. }\end{array}$ \\
\hline
\end{tabular}

(4 ${ }^{\mathrm{a}}$ série, Estudos Sociais.)

Há correção quando o professor "corrige" enunciados do texto-fonte ou a estes se opõe na produção do novo texto.

As reformulações intratextuais correspondem às transformações que ocorrem dentro de um mesmo texto.

5 Ver Gülich e Kotschi (1987), para as atividades de composição textual; Hilgert (1995), sobre a paráfrase na organização textual interativa e, sobretudo, Fuchs (1994), sobre a paráfrase e sua importância para a prática pedagógica. 
Figura 4

\begin{tabular}{|c|c|}
\hline TEXTO-FONTE & TEXTO-MEDIADOR \\
\hline Máxima da relação & $\begin{array}{l}\quad \mathbf{P}-\text { temos uma terceira } \\
\text { máxima ... que é chamada } \\
\text { máxima da relação ... máxima ... } \\
\text { da ... relação ((escrevendo no } \\
\text { quadro)) talvez você por ... por } \\
\text { questões de ... de.: tradução' } \\
\text { mas' fica melhor no lugar de } \\
\text { relação' a palavra relevância } \\
\text { ((escreve essa palavra no } \\
\text { quadro)) ... se vocês tiverem ai } \\
\text { uma folha' coloque entre } \\
\text { parênteses }\end{array}$ \\
\hline
\end{tabular}

Situação experimental - UFRN

Há reformulação parafrástica quando o professor estabelece uma equivalência semântica entre enunciados do texto reformulador e aqueles do texto de origem.

\section{Figura 5}

\begin{tabular}{|c|c|}
\hline TEXTO-FONTE & TEXTO-MEDIADOR \\
\hline $\begin{array}{l}\text { Vocabulário: Mesorregião - É o } \\
\text { conjunto de microrregiões que } \\
\text { apresentam caracteristicas se- } \\
\text { melhantes }\end{array}$ & $\begin{array}{l}P .(. .) \text { quer dizer... são... são } \\
\text { regiões... pequenas regiões... } \\
\text { são pequenas regiões que } \\
\text { apresentam caracte/ preste } \\
\text { atenção! olhe...as... as mesor- } \\
\text { regiões sã::o... são pequenas } \\
\text { regiões que apresentam carac- } \\
\text { teristicas como relevo... clima... } \\
\text { vegetação... solo }\end{array}$ \\
\hline
\end{tabular}

Os dois tipos de reformulação podem ser realizadas por enunciadores diferentes (hetero-reformulações), é o caso dos exemplos citados acima, ou pelo mesmo enunciador (autoreformulações), como no exemplo abaixo: 
"não falar nem mais nem menos que o necessário" è a supermáxima dai ... .não falar nem mais nem menos que o necessário... e tem máximas ... e tem máximas' eh '.:' que são mais' eh:' especificas. (Situação experimental - Aula PA).

As escolhas efetuadas pelo professor nas atividades de reformulação intertextuais podem ser quantitativas e qualitativas (Fuchs, 1994, p. 29-30). Do ponto de vista quantitativo, ele pode expandir, condensar ou manter a simetria entre o texto-fonte e o texto-reformulador. Do ponto de vista qualitativo, ele pode simplificar as informações, visando a torná-las acessiveis ao aluno, ou ao contrário, problematizá-las levantando possibilidades de várias interpretações do textofonte. Tanto a simplificação quanto a problematização do conteúdo, podem, evidentemente, realizar-se dentro de uma gradação semântica mais ou menos complexa conforme a percepção que tem o professor do seu aluno e do nivel de ensino no qual a explicação se efetua.

\section{ASPECTOS PRÁTICOS: COMPETÊNCIA COMUNICATIVA, ATIVIDADES DE REFORMULAÇÃO E FORMAÇÃO DO PROFESSOR}

\section{A função da repetição}

Focalizaremos, aqui, o papel de elementos paralingüísticos e a reformulação intertextual de repetição. Quando a reformulação se realiza através de repetições, as entonações, as ênfases, a silabação, as pausas. o tom (neutro, agressivo etc.) desempenham funções pragmáticas bastante diversas: podem servir para manter uma escuta atenta, enfatizar algum ponto do texto, diminuir ou acelerar o ritmo da explicação, entre outras. De fato, a entonação dada ao texto é a sua primeira interpretação. Na leitura do texto-fonte, o professor desempenha o papel de animador, no sentido etimológico do termo, ele dá alma, dá vida ao texto.

Parece importante distinguir o papel da repetição em duas situações de interação. Em aulas do primeiro ciclo do ensino fundamental, quando se trata, por exemplo, de textos 
de literatura infantil, a leitura de contos, em voz alta, se faz linearmente, e não pode (ou não deve) ser interrompida. A atitude silenciosa do aluno é reveladora de sua atividade criativa e do seu prazer de escutar. Ela implica ainda a validação do papel de professor como contador. Nessa situação, através da atividade de repetição intertextual, o professor desempenha o papel de animador e transmite o conteúdo do conto. Na seqüência da interação, a repetição é praticada pelo aluno que, por sua vez, quer ler o conto (imitar o professor), retomar (repetir) o diálogo dos personagens. As crianças das séries iniciais, freqüentemente, recusam-se a aceitar que se mude a história, que se altere o texto-fonte. A regra básica do jogo na interação ancora-se, nesse caso, na atividade de repetição intertextual.

Nas aulas das outras matérias (geografia, ciências, matemática etc.), a situação é diferente: a leitura linear do texto pelo professor não despertaria o mesmo interesse. Ela deve ser evitada, pela simples razão que esse gênero de discurso não é, a priori, concebido para ser lido em voz alta. Quando, na leitura do conto, o professor empresta sua voz, seu corpo ao autor do texto-fonte, envolvendo a criança com a trama: as personagens e suas ações vão se construindo, pouco a pouco, em suas mentes. Quando o professor transpõe essa situação de leitura para o texto não literário, o efeito é habitualmente inverso, instala-se na sala de aula um clima de total desatenção (Bortoni e Lopes, 1991). A atividade de repetição do texto-fonte na construção do texto-mediador não tem, nesse caso, as mesmas funções. Poderíamos citar inúmeros exemplos em todas as disciplinas do ensino fundamental e médio, nos quais o professor recorre aos seguintes procedimento: leitura (repetição) de partes do texto, marcada por elementos paralingüisticos e pontuada por micromarcadores (Marcuschi, 1988), seguida de reformulações parafrásticas, muito próximas do enunciado do texto-fonte, como no seguinte exemplo (o negrito corresponde à leitura do texto-fonte): 
as classes gramaticais que se referem ao substantivo, né? artigo....adjetivo....numeral.... e pronome concordam com ele em gê:::nero e nú:::mero... aqui você já tem uma definição/..../ concordância nominal, né? concordância nominal ... é quando os substant/eh o adjetivo....o artigo.....o numeral e o pronome concordam em gênero e número com o substantivo,

( $3^{\circ}$ ano ensino médio. Corpus de Gomes, A.S.S., 1997)

O uso de atividades de repetição intertextuais, pelo aluno, na construção do texto-alvo, é associada ao ato de "decorar" e não ao de assimilar conhecimentos ${ }^{6}$. Decorre (decorriam) dessa intuição, frases canônicas utilizadas pelo professor, no processo de ensino/aprendizagem: Não repita! Diga com suas palavras! Agora tente dizer com suas próprias palavras! De fato, o professor solicita uma reformulação intertextual parafrástica, que leva o aluno a realizar uma operação de transformação de enunciados do texto-fonte na produção do texto-alvo.

Admitindo a importância das intervenções formativas (Bronckart, 1997) no processo de ensino/aprendizagem, não poderiamos esquecer dois elementos importantes para a reflexão: por um lado, que o texto-mediador produzido pelo professor em sala de aula é o modelo que segue o aluno (pode até não ser o único) para a produção do texto-alvo, e por outro lado, que é na interação que o aluno vai construindo o seu desempenho como leitor e produtor de textos orais e escritos. No primeiro ciclo do ensino fundamental, quando o aluno convive com um único professor durante o ano letivo, a tendência é que ele internalize a maneira como o professor reformula os conteúdos do texto-fonte. Nas séries subseqüentes, quando passa a conviver com vários professores, ele tende a amoldar-se a cada um deles, num processo espontâneo de mimetismo verbal, cujas causas e conseqüências ainda devem ser investigadas.

Partindo dessas observações, temos procurado sensibilizar professores em formação para a importância da

- Remetemos à análise de Marcuschi (1996) sobre a análise dos livros didáticos, cujos exercicios sugerem mais a "copiação" do que a reflexão. 
construção do texto-mediador e a diferença do seu papel de animador no uso de dois tipos de textos: literário e didático. Em ambos os casos, ele deve se afirmar como animador na sua relação com o texto, os caminhos são, no entanto, diferentes, porque implicam procedimentos lingüisticos e interacionais bastante diversos.

\section{A competência enciclopédica: a expansão das informações}

Evidentemente, uma das primeiras condições exigidas para a explicação dos textos, na interação didática, é que o professor conheça o assunto sobre o qual está falando (competência enciclopédica). Para ilustrar esse ponto, discutiremos a questão da expansão das informações, examinando duas situações de sala de aula: uma aula de geografia da $4^{\mathrm{s}}$ série, e uma aula decorrente de uma situação experimental criada por nosso projeto, dada por um bolsista do PIBIC, com experiência de ensino (ver Passeggi, M. C., 1998).

Como já mencionamos, na maioria das aulas analisadas, a explicação dos conteúdos a partir de textos didáticos realiza-se pela repetição do texto-fonte (leitura), seguida dos comentários do professor. A aula de geografia que analisamos constitui um exemplo representativo do corpus. A voz do professor alterna-se com a voz do autor, ocupando quase o mesmo espaço na construção do texto-mediador. As vozes dos alunos só se impõem em questões relativas à rotina da escola. Constatamos os seguintes percentuais: $36 \%$ do texto-mediador está construido por repetições, realizadas através da leitura do texto-fonte pelo professor; $56 \%$ correspondem aos comentários que se seguem à leitura; $8 \%$ por micro-diálogos entre o professor e o aluno. As reformulações parafrásticas intertextuais imitam os enunciados do texto-fonte, o professor não acrescenta, portanto, nenhuma informação que não esteja no livro.

$\mathrm{Na}$ situação experimental, um dos objetivos era observar como se realizavam as atividades de reformulação intertextuais quando a competência enciclopédica dos informantes havia sido deliberadamente ampliada na fase de 
preparação da interação didática. Observamos que a expansão das informações, realizou-se através de reformulações parafrásticas intertextuais que introduziam informações oriundas de outros textos, revelando a importância do interdiscurso para a construção dos conhecimentos na sala de aula. O professor/bolsista reconheceu, por exemplo, que $83 \%$ dos enunciados do texto-mediador, por ele produzidos, realizaram-se sob a influência de leituras complementares. As reformulações intertextuais de repetição (citações) no total de $11,3 \%$, presentes no texto-mediador, provêm de fontes diversas e têm a função de expandir o texto-fonte, diversificando as informações. Apenas 1,1\% do texto-mediador está construido por repetições do texto-fonte. O desempenho do professor/bolsista permitiu comprovar que a ampliação da competência enciclopédica, na fase de planificação, favorece a fluência na realização das atividades de reformulação intertextuais.

Quais as conseqüências para a formação do aluno, quando o professor limita-se a reformular minimamente o textofonte, na interação didática? A primeira é a própria limitação do conhecimento enciclopédico do aluno que se restringe, quando muito, às informações do texto do livro didático. Ora, como esses textos já resultam de um processo de didatização que simplificam ou condensam as informações, se o professor não fizer um esforço para ilustrá-las com novas situações, ele põe em risco o desenvolvimento do aluno, que por sua vez adota a atitude de "copiação" na produção do texto-alvo. Na escola pública, esse problema se agrava devido às condições de contato com outros textos. No primeiro ciclo, a criança conta pelo menos com os textos do livro didático. No ensino médio, é ainda maior a precariedade desse acesso, sobretudo para os jovens em cursos noturnos, que procuram a escola para completar sua formação, muito deles já no mercado de trabalho. Em muitas aulas do nosso corpus, o triângulo pedagógico que apresentamos no item 1, não se concretiza, pois a relação aluno/texto não se faz diretamente. O texto-fonte é muitas vezes transmitido através de perguntas e respostas que os alunos copiam do quadro. Os conhecimentos chegam, portanto, fragmentados. A estrutura do texto é rompida, faltam- 
Ihe os elementos lingüísticos que asseguram a transição, a progressão temática e a organização do pensamento lógico.

\section{A competência interacional: o contrato pedagógico e a
negociação}

Todo professor, mesmo quando prepara com cuidado as suas aulas, conhece as dificuldades ocasionadas pelo impacto da interação: divergências de interesse, conflito de gerações, divergências de ponto de vista, envolvendo questões de disciplina, de poder, de autoridade e improvisações. Numa perspectiva interacionista, o professor deve atentar para as relações de cooperação e de conflito que se alternam e se complementam no contrato pedagógico, e que constituem objeto de negociação entre ele o aluno. A noção de contrato pressupõe que individuos pertencentes a um mesmo corpo de práticas sociais são suscetiveis de concordarem sobre as representações discursivas dessas práticas sociais (Charaudeau 1983, p. 50). Na sala de aula, estabelece-se um contrato pedagógico, garantido pela instituição escolar, mas ele é de fato negociado entre cada professor e seus alunos, a partir de regras (implícitas ou explícitas), normalmente, colocadas pelo professor.

O reconhecimento da existência de um contrato, entre eles, levanta expectativas de ações intersubjetivas e contribui para a possibilidade de cada um avaliar as suas respectivas intervenções na interação didática. O processo de avaliação é, de fato, o que atribui ao outro o estatuto de agente, i.e., a responsabilidade de intervir de forma ativa na interação (Bronckart, op.cit.)

Charaudeau (1983) distingue no contrato duas dimensões, uma situacional e uma comunicacional. A primeira responde a questões do tipo: estamos aqui para quê? Para desempenhar qual papel? Diz respeito, em particular, ao estatuto social (aluno/professor). A segunda concerne os comportamentos discursivos esperados: o professor tem o direito de perguntar, os alunos são obrigados a responder 
(Maingueneau, 1996). É essa segunda dimensão que nos interessa aqui.

As flechas que se cruzam na base do triângulo pedagogico (Fig. 1), simbolizam a negociação. Para Kramsch (1991), a negociação caracteriza-se por um vai e vem constante entre a significação desejada e o significado produzido pelos co-enunciadores, entre o sentido percebido e o sentido reconstruido, entre os conhecimentos e experiências acumuladas e aquelas a serem adquiridas. A cada momento da aula essa negociação se realiza. Tomaremos como exemplo a abertura das duas aulas que estamos analisando.

Figura 6

\begin{tabular}{|c|c|}
\hline (4a. série, Estudos sociais) & Situação experimental \\
\hline $\begin{array}{l}\text { P. agora a gente vai ver como } \\
\text { se divide nosso estado e também } \\
\text { se divide o país... o pais se divide } \\
\text { em regiões e... e estados então... } \\
\text { nosso estado se divide em } \\
\text { mesorregiões e em microrregiões e } \\
\text { as microrregiões... viu gente? preste } \\
\text { atenção! as microrregiões são } \\
\text { formadas pelos municípios... certo? } \\
\text { os municipios é que formam as } \\
\text { microrregiões e as microrregiões } \\
\text { agrupadas formam o estado aí... } \\
\text { aqui... olhe... }\end{array}$ & 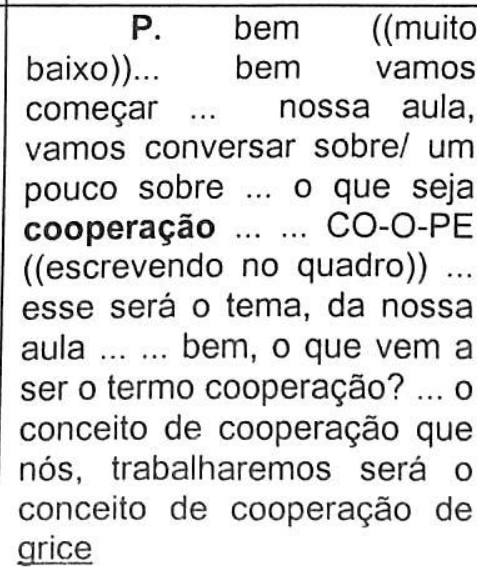 \\
\hline
\end{tabular}

$\mathrm{Na}$ abertura da aula, quando o professor anuncia o tema a ser tratado, ele estabelece um contrato com os alunos, e inicia a negociação ao assumir a posição de mediador do conhecimento contido no texto-fonte. Na aula de Estudos Sociais, o professor se engaja fortemente; de certa forma, se compromete, no sentido de mostrar como se divide o estado do Rio Grande do Norte: "agora a gente vai ver como se divide nosso estado". Na situação experimental, o engajamento é menor: "vamos conversar sobre/ um pouco sobre ... o que seja cooperação". 
Observamos que na aula de Estudos Sociais, ao mesmo tempo em que apresenta o tema da aula (divisão do estado), o professor introduz um assunto que não fará parte dela ("e também se divide o país... o país se divide em regiões"), abrindo expectativas que não serão atendidas. Por outro lado, lança, na abertura, os principais conceitos a ser explicados (mesorregiões, microrregiões, municípios) sem problematizá-los. Na situação experimental, o professor toma o tempo de escrever no quadro o conceito a ser explicado, e reformula o enunciado do texto-fonte através de uma pergunta retórica, com o objetivo de problematizar o tema ("bem, o que vem a ser o termo cooperação?"). Dá início à negociação do sentido, colocando-se na posição inquiridora do aluno (o que é $X$ ?), de quem ele pretende satisfazer a curiosidade, no desenrolar da construção do texto-mediador.

No corpus de nossa pesquisa, que corresponde à realidade da sala de aula da escola pública no estado do Rio Grande do Norte, é muito raro que a negociação entre professor e aluno se realize com base nos conteúdos da matéria. As razões são de diversas ordens. Consideremos apenas a questão do acesso ao texto-fonte. Geralmente, o aluno só tem acesso ao texto-fonte no momento da aula. O seu desconhecimento do conteúdo do texto, acentua a defasagem de conhecimentos (competência enciclopédica) em relação ao professor, limita os questionamentos e inibe a negociação das significações.

A análise dos textos mediadores permite identificar que as dificuldades do professor têm origem, geralmente, no fato de não ter conhecimento suficiente do texto-fonte, por não ter diversificado as suas informações ou, inclusive, por estar lendo o texto pela primeira vez em sala de aula, junto com os alunos.

\section{A competência discursivo-textual: o saber dizer}

O bom desempenho do professor na construção do texto-mediador depende do conhecimento que possui da natureza do texto que vai interpretar (competência discursivotextual), i.e., do gênero do objeto provocador da leitura (Lajolo,1988, p.88). Compreender um texto, perceber sua 
"intenção" não é - ou não é apenas - extrair ou reconstituir informações para integrá-las ao que já se conhece: é identificar a função dessa informação na situação de discurso na qual ela se realiza (Caron, 1983, p. 83)

O livro didático, elaborado na intenção de fornecer informações que conduzam à compreensão da realidade objetiva, constitui-se, igualmente, em "um instrumento crucial para a aquisição da leitura funcional" (Perini, 1988, p.85). Com isso, queremos chamar a atenção para $\circ$ fato de que o texto didático, como qualquer outro texto, veicula dois tipos de saberes: o "saber" historicamente acumulado (o conteúdo da matéria) e uma forma específica do "dizer" (um gênero discursivo).

llustraremos este item, tomando como ponto de reflexão o papel dos enunciados baliza, i.e., dos macromarcadores, na construção dos textos-mediadores. Esses enunciados caracterizam-se pelo uso de pronomes da $1^{\mathrm{a}}$ e $2^{\mathrm{a}}$ pessoa (eu, você, nós); fórmulas no imperativo ("observemos", "analisemos"); verbos no futuro ("começaremos por...") e termos tais como: "primeiramente", "agora" etc. Através desses enunciados, o professor comenta a progressão do texto e procura sublinhar as diversas etapas do seu pensamento. Muitas vezes, retoma o que foi dito anteriormente, antes de introduzir um novo ponto do texto. Esse duplo movimento caracteriza-se por expressões como: "Depois de ter analisado.., considerado $X_{\text {.., }}$ passaremos agora.. " (Coltier, 1988).

Observamos que uso dos enunciados balizas nas aulas do nosso corpus é raro. Os professores recorrem mais freqüentemente aos micromarcadores, do tipo "então", "olha" , "aqui", "preste atenção", "né?", que "dão a impressão de desorganização discursiva, pois são mais próximos da conversação de que de uma aula expositiva" (Marcuschi, 1988, p.41):

agora a gente vai ver como se divide nosso estado e também se divide o pais: o pais se divide em regiōes e e estados, então nosso estado se divide em mesorregiões e em microrregiões e as 
microrregiões, viu gente? preste atenção! as microrregiões são formadas pelos municipios, certo?os municipios é que formam as microrregiões e as microrregiões agrupadas formam o estado /..../ agora é em outra microrregião, certo? olhe a gente tinha ficado aqui, viu, a gente tinha ficado na central central potiguar que é Macau, Angicos, Serra de Santana..

$\mathrm{Na}$ situação experimental, o uso de enunciados baliza é, ao contrário, muito freqüente;

P. bem ((muito baixo))... bem vamos começar .. nossa aula, vamos conversar sobrel um pouco sobre ... o que seja cooperação ... ...CO-O-PE /.../... esse será o tema' da nossa aula ... /.../ Ingedore tem um exemplo muito justo para isso /.../ bem, antes de partir mais para a frente eu gostaria de perguntar I.... eu acho que deu para ficar claro /.../ vamos para ..../.../ voltando ao nosso carro parado /..../ ainda nesse raciocinio /.../

Os enunciados balizas constituem caracteristicas importantes dos textos-mediadores, quando estes estão voltados para a explicação de textos didáticos. Eles desempenham múltiplas funções: a) demarcam as fronteiras entre os diferentes tópicos do texto-fonte; b) asseguram a progressão temática do texto-mediador; c) desenvolvem a escuta atenta do aluno; d) colocam em "cena" os autores estudados para a explicação ("segundo grice /.../ Ingedore tem um exemplo muito justo para isso"); e) permitem, finalmente, que o professor se desloque entre a intenção do autor e a percepção do aluno, como "mediador privilegiado", e se posicione face ao texto-fonte ("bem ...na minha opinião"), marcando a intervenção de sua própria individualidade.

A grande maioria dos professores não atenta para essas características, concentrados no texto-fonte e no textoalvo, raramente se interrogam sobre as competências necessárias para a construção de um texto-mediador de qualidade. Quando assumem a sala de aula pela primeira vez, tendem a adotar, intuitivamente, como modelos, procedimentos lingüísticos e interacionais que observaram em seus próprios 
professores. ${ }^{7}$ Nesse aspecto, o conhecimento sistemático da construção dos discursos da sala de aula deveria fazer parte da formação do professor, sobretudo quando consideramos que o texto por ele produzido terá um caráter exemplar para as produções dos seus alunos.

Se considerarmos a soma das questões aqui levantadas, na escolaridade de um único aluno, não nos surpreenderíamos se ele não fosse capaz de produzir (oralmente ou por escrito) um discurso adequado, coeso e coerente. Imaginemos que esse aluno não tenha acesso ao texto-fonte e/ou a outros textos que tratem dos conteúdos da matéria. Que o texto-fonte Ihe seja transmitido a partir de perguntas e respostas copiadas no quadro, faltando-lhe, portanto, os elementos de sua articulação lógica. Que seus professores recorram a reformulações intertextuais, tais como repetições e paráfrases, sem acrescentar informações complementares, nem problematizar os conteúdos do texto didático. Que, por fim, recorram unicamente aos micromarcadores para articular a progressão temática do texto-mediador. Como esperar, então, que esse aluno exponha um assunto com clareza, saiba argumentar, justificar, explicar, opor-se, acrescentar uma informação, introduzir um argumento contrário etc.?

Lembremos, ainda, que é de acordo com nosso domínio de um gênero que usamos com desembaraço, que descobrimos mais depressa e melhor nossa individualidade neles (quando isso nos é possivel e útil), que refletimos, com maior agilidade, que realizamos, com o máximo de perfeição, o intuito discursivo que livremente concebemos (Bakhtin, 1992, p.304), e que fazemos com que a nossa voz se sobressaia dentre as múltiplas vozes que atravessam o nosso discurso.

A participação em bancas examinadoras de memoriais, junto ao Instituto de Formação de Professores da Universidade Regional do Rio Grande do Norte - URRN, permitiu-nos constatar a representação que têm os graduandos da influência de seus professores na construção de sua identidade social como docentes. 


\section{CONSIDERAÇÕES FINAIS}

É certo que a análise e construção do texto-mediador não ocupa, ainda, o devido lugar na formação dos nossos alunos. Por essa razão, a sala de aula parece situar-se em um horizonte que se desloca na medida em que tentam dele aproximar-se. No entanto, procuramos mostrar que as ações desenvolvidas pelo professor concretizam-se no textomediador e podem ser analisadas, discutidas e melhoradas. As reflexões que apresentamos levam-nos a sugerir alguns pontos para o estudo da interação didática em sala de aula, a serem eventualmente incorporados à formação do professor.

A situação de ensino/aprendizagem formal tem a particularidade de vincular-se a um texto escrito, representativo do saber socio-historicamente acumulado (texto-fonte), desenvolvê-lo pela reconstrução desse saber através de um outro texto, oralmente produzido (texto-mediador), encerrandose na construção de um novo texto escrito (texto-alvo) que mantém, complementa ou transforma o saber inicial. Assim, o domínio das atividades de reformulação intertextuais são cruciais para a produção de novos textos orais e escritos, na construção dos conhecimentos. É através dessas reformulações que professor e aluno estabelecem relações entre o seu pensamento e o pensamento do outro, permitindoIhes opor-se a esses pensamentos ou, ao contrário, adotá-los, complementá-los ou camuflá-los no seu discurso.

A passagem da modalidade de produção escrita (textofonte) para a produção oral (texto-mediador) e desta para a escrita (texto-alvo) solicita procedimentos lingüísticos cognitivos e interacionais de grande relevância para a elaboração do pensamento. Os textos produzidos nessa situação de comunicação trazem as marcas do seu processo de construção; a análise dessas marcas permite inferir a competência comunicativa do enunciador.

Com base nessas reflexões, podemos avançar as seguintes hipóteses, relevantes para a formação do professor:

- quanto mais o professor ampliar sua competência enciclopédica, maior capacidade ele terá de expandir as informações do texto-fonte; 
- quanto mais familiarizado com um determinado gênero, melhor organizará seu pensamento e deixará fluir sua individualidade (competência discursivo-textual);

- quanto mais ele aprimorar seu discurso no nivel do enunciado, maior será a clareza do seu texto (competência lingüistica);

- quanto maior sua capacidade de descentração, para adotar o ponto de vista do aluno, mais ele aumentará a margem de intercompreensão, para explicar um conceito, um fato, um fenômeno e negociar as significações.

Todas essas observações são intuitivamente corretas e fazem parte de uma formação acadêmica de qualidade. Por isso mesmo, é surpreendente que não estejam no escopo das preocupações permanentes dos formadores e, uma vez formados, dos próprios professores. Nesse aspecto, a pesquisa sobre os mecanismos discursivos da sala de aula pode dar uma contribuição essencial para a melhoria da interação didática.

\section{REFERÊNCIAS BIBLIOGRÁFICAS}

ADAM, J-M. Les textes: types et prototypes. Paris: Nathan, 1992.

AUTHIER-REVUZ, J. Hétérogénéité(s) énonciative(s). Langages. Paris: Larousse, n. 73, p. 98-111 1984.

AUTHIER-REVUZ, J. Palavras incertas. Campinas: Unicamp, 1998.

BAKHTIN, M. Estética da criação verbal. São Paulo: Martins Fontes, 1992.

BEACCO, J. C.; MOIRAND, S. Autour des discours de transmission des connaissances. Langages. Paris: Larousse, n. 117, p. 32-53, 1995. 
BORTONI, S. M.; LOPES, I. A. A interação professor $X$ aluno $X$ texto didático. Trabalhos de Lingüística Aplicada. Campinas: Unicamp, n. 18, p.39-60, 1991.

BRONCKART, J-P. Genres et textes, types de discours et opérations psycholinguistiques. Enjeux. Revue de didactique du français. Namur, n. 37/38, p.31-47, 1996 a.

BRONCKART, J-P. L'acquisition des discours. Le Français dans le Monde. Paris:Hachette, p.55-64,1996b.

BRONCKART, J-P. Activite langagière, textes et discours. Lausanne: Delachaux et Niestlé, 1997.

CARON, J. Les régulations du discours. Paris: Presses Universitaires de France, 1983.

CHARAUDEAU, P. Langage et discours. Paris: Hachette, 1983. CHIAPPINI, L. (Coord.) Aprender e ensinar com textos. São Paulo: Cortez, 1997. 3 v.

COLTIER, D. Approches du texte explicatif. Pratiques. Metz, n. 51, p. 3-22, 1986.

CORACINI, M. J. O jogo discursivo na aula de leitura. Campinas:Pontes, 1995. A aula de leitura: um jogo de ilusões. p. 27-33.

DELAMOTTE-LEGRAND, R. Reprises, impositions, résistances et autres inventions: enfants de quatre ans et adultes face au récit. Cahier d'Acquisition et de Pathologie du Langage. Paris: Unversité René Descartes, n. 14, p.59-79, 1997.

FUCHS, C. Paraphrase et énonciation. Paris: Ophrys, 1994.

GOMES, A. S. S. Interação verbal e ensino de gramática. Natal: UFRN, Pós-graduação em Estudos da Linguagem. Trabalho apresentado no exame de qualificação do Mestrado em Lingüística Aplicada. 1997.

GÜLICH, E., KOTSCHI, T. Les actes de la réformulation dans la consultation: La dame de Caluire. In: BANGE, P. (éd). L'analyse des interactions verbales. La dame de Caluire: une consultation. Berne: Peter Lang, 1987. p.15-81. 
GÜLICH. E. Commentaires métadiscursifs et mise en scène de l'élaboration du discours. Cahiers d'Acquisition et de Pathologie du Langage. Paris: Université René Descartes, n. 12, p.29-51, 1994.

HABERMAS, J. Théorie de l'agir communicationnel. Paris: Fayard, 1987. v. 1.

HALTÉ, J-F. Trois points de vue sur l'explicatif. Pratiques. n. 58, p. 3-10, 1988.

HILGERT, J.G. Procedimentos de reformulação: a paráfrase. In: PRETI, D. (Org.). Análise de textos orais. 2. ed. São Paulo: FFLCH/USP, 1995. p. 103-127.

HUSSAYE, J. Le triangle pédagogique. Berne: Peter Lang, 1988.

HYMES, D. Vers la compétence de communication. Paris: Hatier, 1984.

KERBRAT-ORECCHIONI, C. Les Interactions verbales. Paris: Armand Colin, 1990, 1992, 1994. 3 v.

KLEIMAN, A. B. Diálogos truncados e papéis trocados: O estudo da interação no ensino de língua materna. Alfa, n. 37, p.59-74, 1993.

$\mathrm{KRAMSCH}, \mathrm{C}$. Interaction et discours dans la classe de langue. Paris: Hatier/Didier, 1991.

LAJOLO, M. Leitura-literatura: mais do que uma rima. In: ZILBERMAN, R., SILVA, T. E (Org.). Leitura. Perspectivas interdisciplinares. São Paulo: Ática, 1988. p. 87-99.

MAINGUENEAU, D. Les termes clés de l'analyse du discours. Paris: Seuil, 1996.

MARCUSCHI, L. A. Leitura e compreensão do texto falado e escrito como ato individual de uma prática social. In: ZILBERMAN, R., SILVA, T. E (Org.). Leitura. Perspectivas interdisciplinares. São Paulo: Ática, 1988. p. 38-57.

MARCUSCHI, L. A. Exercícios de compreensão ou copiação nos manuais de ensino de língua. Em aberto. Brasília: MEC, a. 16, n. 69, p. 63-82, 1996. 
MOIRAND, S. Une grammaire des textes et des dialogues. Paris: Hachette, 1990

MOIRAND, S. et al. Parcours linguistiques de discours spécialisés. Berne: Lang, 1994.

MOIRAND, S. PEYTARD, J. Discours et enseignement $d u$ français. Paris: Hachette, 1992.

PASSEGGI, L. Abordagens em lingüistica aplicada. Natal: EDUFRN, 1998a. A lingüistica Aplicada nas ciências da linguagem. p. 29-54.

PASSEGGI, L. Os discursos da sala de aula. Para uma retórica da interação didática. Vivência. Natal: EDUFRN, v. 12, n. 1, p. 87-102. 1998b.

PASSEGGI, M. C. A explicação na interação didática. Vivência. Natal: EDUFRN, v. 12, n. 1, p. 55-75. 1998 b.

PASSEGGI, M. C. Discurso explicativo e uso do livro didático em sala de aula. In: PASSEGGI, L. (Org.). Abordagens em lingüística aplicada. Natal: EDUFRN, 1998. p. 147-168.

PERINI, M. A leitura funcional e a dupla função do texto didático. In: ZILBERMAN, R., SILVA, T. E (Org.) Leitura. Perspectivas interdisciplinaires. São Paulo: Ática, 1988. p. 78-86.

VION, R. La Communication verbale. Paris: Hachette, 1992. 